\title{
The role and responsibilities of industrial photonics and laser companies in the training of the next generation of scientists and engineers
}

Kamran Mobarhan

Kamran S. Mobarhan, "The role and responsibilities of industrial photonics and laser companies in the training of the next generation of scientists and engineers," Proc. SPIE 9664, Ninth International Topical Meeting on Education and Training in Optics and Photonics, 96641A (24 October 2005); doi: $10.1117 / 12.2207564$

Event: Ninth International Topical Meeting on Education and Training in Optics and Photonics, 2005, Marseille, France 
Ref ETOP014

\title{
The role and responsibilities of industrial photonics and laser companies in the training of the next generation of scientists and engineers.
}

\author{
Kamran S. Mobarhan, Ph.D.
}

Product Marketing Manager, New Focus Division of Bookham Technology, San Jose, California, USA

\begin{abstract}
The science of photonics and optics has emerged to be one of the leading fields of scientific and engineering innovation in the 21 st century. One key factor in keeping this wave of innovation and advancement going at full momentum is the effort spent in the training and educating of the next generation of photonics scientists and engineers. More and more students are becoming interested in this field at a younger age, starting at high school or even earlier. This talk explores the role and responsibilities of the industrial photonics and lasers companies in reaching and encouraging this next generation of professionals.
\end{abstract}

\section{Summary}

For those of us who the took the path of playing with Lego sets all the way to becoming professional scientists, engineers, and business leaders in the photonics and lasers industry, as well as in academia, it is always fascinating to see a young individual just beginning to embark on a similar adventure. Traditionally school teachers and college professors have always been in a position to help guide such young individuals in the right direction and help them get the right training and education in order to become successful scientists and engineers in the photonics field. However, one cannot help wonder what is the optimum role that industrial corporations, and professionals working at these companies, can play in order to reach and encourage this next generation of professionals.

The most important help a business or technical professional, who works in the photonics and lasers industry, can provide to a young person who is interested in a future in this field is the providing of an overall perspective that can only be gained through years of experience. Sharing the tale of how one evolved from being a young student of photonics into an industry professional is one of the most important contributions that any professional can make to the career development efforts of the young student.

A typical high school student might very well know that he or she likes mathematics or likes engineering projects. But this person may have no clue what it means, or what it takes, to turn this personal interest into something that down the road can put him or her in a position in life that creates professional satisfaction and success, financial well being, and most important of all an overall sense of happiness in life.

By sharing with the student our story of how we moved along a similar path we will be able to provide a perspective for that individual that he or she may otherwise not get for 
many years to come. We can do this most effectively through giving seminars and lectures at colleges as well as at high schools. We should bring to the attention of the students that their professional career options are far more diverse than they may be aware of.

Should the young student who is interested in lasers and engineering listen to the story of a dozen professionals who are working in the photonics industry in various and entirely different capacities, he or she will be able to develop a better sense of appreciation for what are the professional options and the various career paths available to him or her. The student will be able to better explore his or her options as a future research scientist, industrial manufacturing engineer, design engineer, product line manager, business development manager, director of marketing, or an intellectual property specialist working at a law firm. The notion of such potential career options may not readily present themselves to the mind of a young student of mathematics or engineering.

It is highly beneficial to increase the level and the frequency of interaction, as well as more in-depth collaboration, between the high schools and undergraduate engineering institutions and the professionals working at industrial corporations.

In addition to giving lectures and seminars at colleges and high schools these industry professionals can also organize technology and product demonstration events at these academic institutions.

For example, imagine a major photonics and lasers company organizing a half day event at a high school in which they put on display a non-operating high power laser system with all its internal components available for the students to see and touch. An engineer can explain to the students the engineering design and the technology aspects of the laser while a marketing manager explains to the students how a business operates in order to bring to market such high-tech products.

Another effective means of increasing the level of interaction between industrial corporations and educational institutions is the establishment of internship programs, at industrial corporations, which are designed specifically for younger students such as juniors or seniors in high schools as well as for first or second year undergraduate students.

For example, imagine the benefits of a three months long summer internship for a young enthusiastic student at a company which specializes in lasers and also has a portfolio of products related to educational laboratory kits. Such joint ventures will greatly benefit the student, the academic institution, the industrial company, and the entire scientific and industrial community as a whole.

These types of industry driven and supported programs could potentially lead to these students coming up with new innovations that would have potential market value to a large group of people. Why not help and support such students, and provide guidance to them, so that they can begin to take the first steps in establishing a new company with a viable business plan while still in high school or while going through early college years. 
By the time such individuals graduate from college they may be in a position to hire their fellow classmates. Also because they have created a mission and a professional goal for themselves, they will be able to tailor their university course of studies in a more optimum fashion.

They can choose and tailor their courses in such manner that by the end of four years they would be well equipped with the right tools in order to succeed in the business venture they have already embarked upon, as opposed to going through a standard four year college program and upon graduation wondering what to do with their education and what type of job to get. Instead of looking for job opportunities they will be able to offer job opportunities to others.

There is a relatively wide gap between universities generating novel ideas and the introduction of these ideas to market in the form of well developed technologies and products. In an effort to shrink this gap, many universities have established research parks which serve as a technology incubator facility in which university students, faculty, and researchers have a chance to launch and bring to market their technology concepts through forming of new start-up companies and spin-off research centers.

Business managers at photonics and laser companies are in a position to launch and support joint business development programs between these university spin-off new start-up companies and the well established larger corporations. An increased level of collaboration in this area, between universities and companies, will result in the young professionals such as graduating engineering or physics students getting a jump start in their professional career development efforts. The professional successes of these students will in turn encourage younger students to gravitate to the photonics sciences field. More importantly the successes of these new companies launched and driven by recent graduates, or university students, will create new job opportunities for those same students as well as for future graduates. Business managers at larger more established companies are in a position to facilitate this and thus contribute in a significant and meaningful way to the training and professional advancement of the next generation of photonics professionals. 